REVUE DE L'INSTITUT

FRANÇAIS D'HISTOIRE

EN ALLEMAGNE

\section{Revue de l'IFHA}

Revue de l'Institut français d'histoire en Allemagne

$2 \mid 2010$

IFHA 2

\title{
Les Rendez-vous de l'histoire à Weimar, première rencontre : «Wagnis Demokratie(n) / oser la démocratie »
}

Weimar, 4 octobre 2009

Thomas Lienhard

\section{OpenEdition}

Journals

Édition électronique

URL : http://journals.openedition.org/ifha/220

DOI : $10.4000 /$ ifha. 220

ISSN : 2198-8943

Éditeur

IFRA - Institut franco-allemand (sciences historiques et sociales)

Édition imprimée

Date de publication : 1 janvier 2010

Pagination : $43-45$

ISSN : 2190-0078

Référence électronique

Thomas Lienhard, "Les Rendez-vous de l'histoire à Weimar, première rencontre : « Wagnis

Demokratie(n) / oser la démocratie » », Revue de l'IFHA [En ligne], 2 | 2010, mis en ligne le 01 février

2013, consulté le 15 septembre 2020. URL : http://journals.openedition.org/ifha/220

Ce document a été généré automatiquement le 15 septembre 2020.

(CIFHA 


\title{
Les Rendez-vous de l'histoire à Weimar, première rencontre : « Wagnis Demokratie(n) / oser la démocratie »
}

Weimar, 4 octobre 2009

\author{
Thomas Lienhard
}

\section{NOTE DE L'ÉDITEUR}

Rapport établi par Thomas Lienhard

1 Du 2 au 4 octobre 2009, la ville de Weimar et le Bureau Culturel de Thuringe ont organisé avec le soutien de l'IFHA son premier «Rendez-vous de l'histoire» sur le thème "Oser la démocratie ». Sur le même modèle que les rencontres analogues de Blois, l'événement était destiné à attirer vers l'histoire un large public, et fut couronné de succès à cet égard : ce furent près de mille invités de générations très différentes qui vinrent assister aux 28 manifestations organisées durant ces trois jours. L'objectif intellectuel, élaboré par un conseil scientifique composé de chercheurs allemands, français et polonais, consistait à discuter la notion de démocratie en la replaçant dans des contextes temporels et culturels divers; il s'agissait également de sonder les relations (éventuellement de concurrence) entre ce système politique et d'autres régimes.

2 Pour aboutir à ce résultat tout en assurant une participation active $\mathrm{du}$ public, les médias les plus divers furent employés. On projeta des films, introduits par des experts et suivis de débats. On associa des écoles à la manifestation, notamment par le biais d'un atelier musical dans lequel la chansonnière Corinne Douarre encouragea les élèves à composer sur le thème de la démocratie. Surtout, on multiplia les conférences et tables rondes, dont la liste est fournie plus bas et qui soulignèrent en particulier le 
risque de populisme inhérent à toute démocratie en Europe de l'Est et de l'Ouest et qui s'interrogèrent sur les moyens d'échapper à cette dérive. Là encore, les réactions de l'assistance furent vives et le débat fut, si l'on nous passe l'expression, au rendez-vous.

Devant le succès de cette première manifestation, la ville de Weimar s'est déjà engagée à proposer l'an prochain une nouvelle édition de ces «Rendez-vous de l'histoire », qui portera sur le thème « Reisen in (Un)Bekanntes ».

4 Programme détaillé de la rencontre en 2009:

\begin{tabular}{|c|c|c|}
\hline Horaire & Orateurs & Thème \\
\hline $\begin{array}{l}1 / 10 / 09 \\
17 \mathrm{~h}\end{array}$ & $\begin{array}{l}\text { Daniel Henri (Versailles), Ilas Körner-Wellershaus } \\
\text { (Leipzig), Kai Sauer (Weimar) Modération: Thomas } \\
\text { Serrier (Francfort/Oder) }\end{array}$ & $\begin{array}{l}\text { Des jeunes Français et Allemands } \\
\text { apprennent la même histoire: } \\
\text { le manuel d'histoire franco- } \\
\text { allemand }\end{array}$ \\
\hline $\begin{array}{l}2 / 10 / 09 \\
18 \mathrm{~h}\end{array}$ & Erhard Eppler (Schwäbisch Hall) & $\begin{array}{l}\text { Chemins allemands vers la } \\
\text { démocratie }\end{array}$ \\
\hline $\begin{array}{l}3 / 10 / 09 \\
12 \mathrm{~h}\end{array}$ & $\begin{array}{l}\text { Wilfried Nippel (Berlin), Michael Zeuske (Cologne), } \\
\text { Reinhard Schulze (Berne), Modération: Thomas Kroll } \\
\text { (Iéna) }\end{array}$ & $\begin{array}{l}\text { «De combien d'histoire a besoin } \\
\text { la démocratie?» Signification } \\
\text { actuelle des concepts historiques } \\
\text { de démocratie }\end{array}$ \\
\hline $\begin{array}{l}3 / 10 / 09 \\
13 \mathrm{~h}\end{array}$ & $\begin{array}{l}\text { Michael Dreyer (Iéna), Fabien Perrier (Paris), Torsten } \\
\text { Oppelland (Iéna), Modération: Fabrice d'Almeida } \\
\text { (Paris) }\end{array}$ & $\begin{array}{l}\text { Yes, we can ! - la personnification } \\
\text { de la politique : chance ou risque } \\
\text { pour la démocratie }\end{array}$ \\
\hline $\begin{array}{l}3 / 10 / 09 \\
14 \mathrm{~h}\end{array}$ & $\begin{array}{l}\text { Kai-Olaf Lang (Berlin), Frank Decker (Bonn), Günther } \\
\text { Pallaver (Innsbruck), Modération: Alice Volkwein } \\
\text { (Paris) }\end{array}$ & $\begin{array}{l}\text { Vulnérable démocratie - } \\
\text { Populismes et antidémocratisme } \\
\text { sous couvert de démocratie }\end{array}$ \\
\hline $\begin{array}{l}3 / 10 / 09 \\
15 \mathrm{~h}\end{array}$ & $\begin{array}{l}\text { Olaf Weber (Weimar), Helmut Seemann (Weimar), } \\
\text { Helmut Orpel (Mannheim), Modération: Torsten } \\
\text { Unger (Erfurt) }\end{array}$ & $\begin{array}{l}\text { Démocratie et architecture : du } \\
\text { Bauhaus aux HLM }\end{array}$ \\
\hline $\begin{array}{l}3 / 10 / 09 \\
16 \mathrm{~h}\end{array}$ & Henri Ménudier (Paris) & $\begin{array}{l}\text { État de droit ou démocratie } \\
\text { populaire }\end{array}$ \\
\hline $\begin{array}{l}3 / 10 / 09 \\
17 \mathrm{~h}\end{array}$ & $\begin{array}{l}\text { Rudolf von Thadden (Göttingen) interrogé par } \\
\text { Thomas Serrier (Francfort/Oder) }\end{array}$ & De la Seine à la Vistule \\
\hline $\begin{array}{l}3 / 10 / 09 \\
18 \mathrm{~h}\end{array}$ & $\begin{array}{l}\text { Joachim Linck (Erfurt), Ralf-Uwe Beck (Berlin), } \\
\text { Modération : Ulrike Greim (Erfurt) }\end{array}$ & $\begin{array}{lll}\text { «Nous sommes le peuple... ! ». } & \\
\text { Démocratie } & \text { directer ou } \\
\text { parlementaire? } & & \end{array}$ \\
\hline $\begin{array}{l}3 / 10 / 09 \\
19 \mathrm{~h}\end{array}$ & Alf Rößner (Weimar) & $\begin{array}{l}\text { Entre éclair et fontaine coloniale. } \\
\text { Remarques sur les monuments } \\
\text { commémoratifs des années } 1920 \text { à } \\
\text { Weimar }\end{array}$ \\
\hline
\end{tabular}




\begin{tabular}{|c|c|c|}
\hline $\begin{array}{l}3 / 10 / 09 \\
20 \mathrm{~h}\end{array}$ & & $\begin{array}{l}\text { Histoire(s) en musique - Des } \\
\text { élèves du lycée Goethe écrivent } \\
\text { des chansons }\end{array}$ \\
\hline $\begin{array}{l}4 / 10 / 09 \\
10 h\end{array}$ & $\begin{array}{l}\text { Claudia Kraft (Erfurt), Krzysztof Ruchniewicz } \\
\text { (Wroclaw), Étienne François (Nantes et Berlin), Ilko- } \\
\text { Sascha Kowalczuk (Berlin), Modération: Thomas } \\
\text { Serrier (Francfort/Oder) }\end{array}$ & $\begin{array}{l}\text { «Merci, ça suffit ». Les } \\
\text { révolutions en Europe } 1789-1989\end{array}$ \\
\hline $\begin{array}{l}4 / 10 / 09 \\
11 \mathrm{~h}\end{array}$ & Christian Delporte (Versailles) & $\begin{array}{l}\text { Le pouvoir politique des médias. } \\
\text { La communication politique } \\
\text { aujourd'hui }\end{array}$ \\
\hline $\begin{array}{l}4 / 10 / 09 \\
14 \mathrm{~h}\end{array}$ & Dietmar Rothermund (Ratisbonne) & $\begin{array}{l}\text { Démocratique, le monde? } \\
\text { Démocratie et mondialisation }\end{array}$ \\
\hline $\begin{array}{l}4 / 10 / 09 \\
15 \mathrm{~h}\end{array}$ & Justus Ulbricht (Dresde) & $\begin{array}{l}\text { Les héros inconnus de Weimar - } \\
\text { premières } \\
\text { démocratiques après } 1918\end{array}$ \\
\hline $\begin{array}{l}4 / 10 / 09 \\
17 \mathrm{~h}\end{array}$ & $\begin{array}{l}\text { Kurt Shell (Francfort/Main) interrogé par Michael } \\
\text { Dreyer (Iéna) }\end{array}$ & $\begin{array}{l}\text { Entre Hitler et McCarthy - une vie } \\
\text { démocratique en temps de } \\
\text { dictature }\end{array}$ \\
\hline $\begin{array}{l}4 / 10 / 09 \\
18 \mathrm{~h}\end{array}$ & $\begin{array}{l}\text { Volkhard Knigge (Weimar / Buchenwald), Étienne } \\
\text { François (Nantes et Berlin), propos d'introduction de } \\
\text { Bertand Herz, ancien détenu et citoyen d'honneur de } \\
\text { la ville de Weimar depuis le } 3 \text { octobre 2009, } \\
\text { Modération : Justus Ulbricht (Dresde) }\end{array}$ & $\begin{array}{l}\text { L'importance de la mémoire pour } \\
\text { l'avenir de la démocratie }\end{array}$ \\
\hline $\begin{array}{l}4 / 10 / 09 \\
20 h\end{array}$ & $\begin{array}{l}\text { Anthony Rowley (Paris), Simona de Julio } \\
\text { (Strasbourg), Modération : Pascale Laborier (Berlin) }\end{array}$ & $\begin{array}{l}\text { Démocratie pour gourmets. } \\
\text { Histoire(s) de la démocratie en } \\
\text { petites bouchées }\end{array}$ \\
\hline
\end{tabular}

